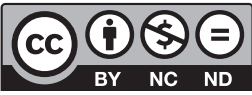

Estudos Teológicos foi licenciado com uma Licença Creative Commons Atribuição - NãoComercial - SemDerivados 3.0 Não Adaptada

http://dx.doi.org/10.22351/et.v58i2.3418

\title{
Pensamento na fronteira e Teologia Prática: UM DIÁLOGO COM O SUMA KAWSAY / SUMA QAMAÑA OU BUEN VIVIR ${ }^{1}$
}

Border Thinking and Practical Theology:

a dialogue with the suma kawsay/suma qamaña or buen vivir

\section{Júlio Cézar Adam² Valburga Schmiedt Streck $^{3}$ Danilo Romeu Streck ${ }^{4}$}

\begin{abstract}
Resumo: Este texto tem como objetivo contribuir com as discussões sobre a Teologia Prática em relação à sociedade a partir de uma perspectiva da assim chamada epistemologia do sul, entendendo o sul em uma forma metafórica, representando alternativas à visão hegemônica do mundo. Entendemos que a Teologia Prática tem um desafio importante de ajudar as igrejas e aqueles expostos à fé cristã em reconhecer o seu contexto social-histórico e com isso promover o chamado de vida em abundância. $\mathrm{O}$ argumento neste texto é que a Teologia Prática pode aprender de diferentes cosmovisões e de práticas sociais que emergem das antigas tradições culturais latino-americanas, contribuindo dessa forma para uma abertura da teologia tradicional baseada na epistemologia eurocêntrica, por mais sofisticada que essa se apresenta. A primeira parte deste texto apresenta uma breve reflexão sobre a discussão epistemológica na América Latina e em outras partes do mundo na perspectiva da metáfora do sul. Segue uma apresentação do buen vivir, que nas últimas décadas tem sido incorporado no repertório de alternativas. Por último, há uma reflexão da contribuição do buen vivir com a Teologia Prática.
\end{abstract}

Palavras-chave: Epistemologias do Sul. Justiça social. Teologia Prática. Buen vivir. Espiritualidade.

1 O artigo foi recebido em 11 de agosto de 2018 e aprovado em 05 de outubro de 2018 com base nas avaliações dos pareceristas ad hoc.

Os conceitos de suma kawsay/suma qamaña das línguas andinas, ou buen vivir em espanhol, são considerados uma narrativa pós-desenvolvimento na América Latina de maneira similar ao conceito ubuntu para a África. Vamos usar a versão em espanhol neste artigo.

2 Professor adjunto de Teologia Prática na Faculdades EST, em São Leopoldo/RS, Brasil. Contato: julio3@ est.edu.br

3 Pesquisadora associada na Faculdades EST, em São Leopoldo/RS, Brasil. Contato: valburga.schmiedt@ gmail.com

4 Professor titular do Programa de Pós-Graduação em Educação na Universidade do Vale do Rio dos Sinos/ UNISINOS, em São Leopoldo/RS, Brasil. Contato: streckdr@gmail.com 
Abstract: This text aims to contribute to the discussions about Practical Theology in relation to society from a perspective of the so-called epistemology of the South, understanding the South in a metaphorical form, representing alternatives to the hegemonic vision of the world. We understand that Practical Theology has an important challenge in helping churches and those exposed to the Christian faith to recognize its social-historical context and thereby promote the call of life in abundance. The argument in this text is that Practical Theology can learn from different worldviews and social practices that emerge from the ancient Latin American cultural traditions, thus contributing to an opening of traditional theology based on Eurocentric epistemology, however sophisticated it appears. The first part of this text presents a brief reflection on the epistemological discussion in Latin America and in other parts of the world from the perspective of the metaphor of the South. It follows a presentation of buen vivir, which in recent decades has been incorporated into the repertoire of alternatives. Finally, there is a reflection on the contribution of buen vivir to practical theology.

Keywords: Epistemology of the South. Social justice. Buen vivir. Spirituality. Practical Theology.

\title{
Introdução
}

\author{
La lucha indigena y afrodescendiente \\ significa una lucha por otro tipo de \\ desarrollo, por otro tipo de manejo de \\ recursos, y ahi representan a la humanidad \\ en su aspiración de sobrevivir. \\ Boaventura de Souza Santos
}

Neste artigo pretendemos contribuir para as discussões em torno da Teologia Prática em sua relação com a sociedade. Fazemos isso a partir da perspectiva do que tem sido chamado de "sul epistêmico", entendendo o sul em seu sentido metafórico, representando visões alternativas à visão de mundo moderna hegemônica. Neste sentido, há um sul no norte como há um norte no sul.

É nosso entendimento que a Teologia Prática tem um desafio particular em termos de ajudar a igreja e aqueles que defendem a fé cristã em ver o indivíduo dentro de seu contexto sócio-histórico, cumprindo assim o chamado para promover a vida em sua plenitude para todas as pessoas. Isso representa um desafio especial, dada a multiplicidade de expressões religiosas e práticas sociais que podem ser encontradas na América Latina. É preciso reconhecer que, quando nos referimos à Teologia Prática na América Latina, estamos falando de um grupo religioso bastante pequeno composto pelas igrejas protestantes tradicionais. Teologia Prática não é um conceito comum à Igreja Católica Romana, cuja prática é dividida em pastorais específicas (com filhos,

5 SANTOS, Boaventura de Sousa; MENESES, Maria Paula (Ed.). Epistemologias do Sul. São Paulo: Cortez, 2010. p. 25 . 
famílias, jovens, camponeses, trabalhadores etc.), bem como para as igrejas pentecostais, que geralmente carecem de educação teológica formal.

$\mathrm{O}$ argumento neste artigo é que a Teologia Prática pode aprender de maneiras de conhecer, de visões de mundo e de práticas sociais que emergem das cinzas da exploração colonial. O suma kawsay (Quéchua), o suma qamaña (Aymara) ou o buen viver (espanhol) representam um dos desafios emergentes na América Latina. $\mathrm{O}$ pensamento de fronteira refere-se a uma posição epistemológica em que, embora reconhecendo que o mundo do buen vivir está longe da vida cotidiana nas sociedades tradicionais, existe a possibilidade de nos colocar à margem e reconhecer alternativas que, vindas do passado indígena, implicam aprendizagens para garantir uma vida mais digna e gratificante hoje e talvez um futuro com vida. Nesse sentido, encontra ressonância com outras práticas sociais ancestrais como o ubuntu na África do Sul.

A teologia é uma parte muito importante das concepções ocidentais clássicas sobre a relação com o conhecimento e o saber. Na medida em que essas concepções estão sob suspeita em relação à sua reivindicação de universalidade, a teologia também é confrontada com o desafio de se abrir para caminhos alternativos a fim de lidar com outros seres humanos, com a natureza e com os modos de entender o mundo. A teologia eurocêntrica, por mais sofisticada que seja, é também um desenvolvimento "provincial".

A primeira parte do texto será dedicada a apresentar uma breve visão de algumas discussões epistemológicas que atualmente são realizadas na América Latina e em outras partes do mundo a partir da perspectiva do sul metafórico. Segue-se uma apresentação do buen vivir, que nas últimas décadas foi incorporado ao repertório de alternativas sociais e políticas. O último tópico reflete sobre a contribuição dessa abordagem epistemológica, particularmente o buen vivir, para a Teologia Prática.

\section{Emergências epistemológicas e teológicas}

A conquista de Abya Yala, como alguns dos povos originários que viviam nessa parte do mundo costumavam chamar suas terras (o termo vem do povo Kuna do Panamá), representou um pachacuti, que para os povos andinos significava o mundo de cabeça para baixo. O cristianismo desempenhou um papel importante na conquista das mentes, corpos e corações das pessoas, seja usando métodos pedagógicos "suaves" como o teatro, como fez o padre José de Anchieta no Brasil, ou ensinando com o chicote, como descrito nos desenhos de Guamán Poma de Ayala no início do século XVII. ${ }^{6}$

Fato inegável é que a fé cristã fazia parte do encontro violento nas Américas, como aconteceu em outras partes do mundo. Aníbal Quijano ${ }^{7}$ cunhou o conceito de

6 AYALA, Felipe Guamán Poma de. Nueva Corónica y Buen Gobierno. México: Fondo de Cultura Económica, 1993.

7 QUIJANO, Aníbal. Coloniality of Power, Eurocentrism, and Latin America. In: MORAÑA, Mabel; DUSSEL, Enrique; JÁUREGUI, Carlos (Ed.). Coloniality at large: Latin America and the Postcolonial debate. Durham; London: Duke University Press, 2008. p. 181-224. 
colonialidade, remetendo-o à ideia de raça, categoria mental básica inventada na modernidade para diferenciar entre os conquistadores e os conquistados. As discussões sobre a linha divisória entre o humano e o não humano pediram a interferência da mais alta autoridade eclesiástica. Em 1537, o papa Paulo III emitiu uma bula (Bula Veritas Ipsa) declarando que "os índios das partes ocidentais, e os do meio-dia, e os mais povos (escravos)" eram dignos de receber o Evangelho, o que significava ser convertido e catequizado.

Isso, no entanto, está muito longe de reconhecer os modos pelos quais os conquistados conheciam, adoravam ou criam. Boaventura de Sousa Santos ${ }^{8}$ argumenta que o pensamento ocidental moderno é um pensamento abissal, constituído por um sistema que distingue o visível do invisível, separado em dois universos distintos, de modo que o invisível apenas legitima o visível. Um exemplo é o monopólio da ciência moderna para identificar o que é falso ou verdadeiro. Mesmo as discussões modernas entre ciência e teologia/crença ocorrem do lado do visível, escondendo o que existe do outro lado da linha, e descartando-o como crença falsa ou superstição. Enrique Dussel, nesse sentido, refere-se à "descoberta" da América como sendo "um encobrimento do outro".

Na perspectiva descolonial, a Teologia da Libertação na América Latina tentou incluir mais vozes em seu repertório. A "opção preferencial pelos pobres" (Conferência dos Bispos Latino-Americanos em Puebla, 1979) foi ampliada para incluir uma diversidade de assuntos dentro da igreja e na sociedade como um todo. Michel Löwy ${ }^{10}$, analisando esse processo, prefere falar de cristianismo de libertação, do qual a Teologia da Libertação teria sido o topo visível do iceberg. O cristianismo de libertação é a expressão de um vasto movimento social que se estende desde os anos 1960. Desse movimento faz parte o Movimento dos Trabalhadores Rurais Sem Terra (MST), no Brasil, mas também encontra expressão em organizações como a Conferência Nacional Indígena no Equador (CONAIE).

Esses movimentos são sinais de que a crise que abrange a crescente brecha entre ricos e pobres ${ }^{11}$, a exploração da natureza como um "recurso" e a concepção linear de desenvolvimento também estimulam o movimento de resistência, bem como o surgimento de alternativas. No próximo tópico, veremos mais de perto um deles.

\footnotetext{
SANTOS; MENESES, 2010, p. 23.

9 DUSSEL, Enrique. 1492: O encobrimento do outro: A origem do mito da modernidade. Petrópolis: Vozes, 1993. p. 27.

${ }^{10}$ LÖWY, Michel. The historical meaning of Christianity of Liberation in Latin America. In: MORAÑA; DUSSEL; JÁUREGUI (Ed.), 2008, p. 351-359.

${ }^{11}$ PIKETTY, Thomas. Capital in the Twenty-first Century. Cambridge: Harvard University Press, 2014. p. 237-430. Cf. O capital no século XXI. Trad. Monica Baumgarten de Bolle. Rio de Janeiro: Intrínseca, 2014.
} 


\section{O conceito de suma kawsay / suma qamaña, ou buen vivir}

O conceito de buen vivir inspira-se nas antigas filosofias e cosmologias indígenas dos povos indígenas andinos, nas quais a compreensão ocidental do desenvolvimento moderno não existe. Muitos dos países da América do Sul cresceram economicamente nos últimos anos, e esse crescimento muitas vezes se deu à custa da degradação ambiental através do extrativismo desregulamentado, que não melhorou a vida das pessoas e resultou na perpetuação da pobreza. Não era incomum que os povos indígenas fossem deslocados de suas terras, e isso resultou em inquietação e movimentos de resistência. ${ }^{12}$

Durante muitos anos, os líderes indígenas, através dos movimentos sociais, tentaram resgatar o conceito de suma kawsay/suma qamaña ou buen vivir dos tempos pré-coloniais, no qual propõem um conceito comum de maneiras de se opor à obsessão capitalista de consumo e acumulação de riqueza, e à corrida extrativista que agride o meio ambiente. Isso pode ser visto como uma expressão dos esforços de descolonização e como uma tentativa de fortalecer as identidades culturais. Vários grupos de indígenas andinos olham para suas antigas tradições e formulam significados para o buen vivir. ${ }^{13}$ Não há documentos escritos pelas culturas antigas e a busca está relacionada com as tradições orais e as memórias. Nesse sentido, é compreensível que seja um conceito que ainda está sendo elaborado e não vem como uma formulação teórica fechada. ${ }^{14}$

O buen vivir rejeita a ideia de um processo de desenvolvimento linear e propõe uma conexão entre os seres humanos e a natureza, desafia o consumo frenético de bens materiais e defende uma relação de comércio justo que satisfaça os seres humanos e não prejudique a natureza. $\mathrm{O}$ modo dualista e excludente de pensar a cultura ocidental que, enquanto domina o outro, projeta todo o mal sobre ele, não está no horizonte do pensamento inclusivo dos povos andinos. Ganhar mais, ser melhor, impor-se sobre o outro como formas de construir identidade estão em oposição à compreensão do buen vivir. Pode-se dizer que é um movimento filosófico que enfatiza uma mudança na maneira como as pessoas vivem e abordam a vida.

Esse movimento constitui uma alternativa ao moderno capitalismo colonial ocidental, no qual as antigas formas de racismo e colonialismo ainda persistem nas estruturas do Estado. ${ }^{15}$ A principal proposta do movimento é o apelo para olhar o conceito de buen vivir das culturas indígenas e tornar visível que os povos indígenas foram capazes de viver em harmonia durante milênios com a natureza, consumir e usar os recursos necessários para sobreviver e não mais do que o ecossistema pode suportar. Propõe mudanças drásticas para a sociedade capitalista no modo de viver, consumir e produzir. O entendimento indígena é que o planeta está doente e que rios, oceanos e

${ }^{12}$ GUDYNAS, Eduardo. Buen Vivir: Today's tomorrow. Development, ano 54, n. 4, p. 441-447, 2011. p. 441.

${ }^{13}$ GUDYNAS, 2011, p. 441.

${ }^{14}$ FELIX, Gloria Alicia Caudillo. El buen vivir: un diálogo intercultural. Ra-Ximhai, ano 8, n. 2, p. 345-363, 2012. p. 358.

${ }^{15}$ QUIJANO, 2008, p. 183. 
florestas estão enfrentando uma catástrofe ambiental e humana. Nesse entendimento, a Pachamama, ou a Mãe Terra, está agonizando devido ao uso indiscriminado que se faz dela. Como todos os seres humanos e animais são filhos dela, eles também sofrem junto. Nesse entendimento, a natureza é considerada um sujeito: tem direitos como outros sujeitos e deve ser cuidada e respeitada como tal. Há dois aspectos centrais no conceito de buen vivir: a) pertencer à natureza (os seres humanos são parte integrante dela); b) a sensação de que alguém pertence a uma comunidade. Ciclos de vida de todas as espécies diferentes são importantes, e rituais e restrições são considerados como parte do modo de viver.

É importante mencionar que o conceito de buen vivir permitiu que as populações indígenas se unissem em torno de um entendimento semelhante de outro modo de viver e elaborassem propostas para entrar em diálogo com a cultura hegemônica na América Latina. Muitos dos líderes indígenas foram educados, ensinam em universidades da América Latina e são ativos na política. Essas pessoas ajudaram a articular os conceitos do buen vivir de seus ancestrais e a apresentar propostas que desafiavam a cultura hegemônica do colonizador branco. Os movimentos sociais indígenas foram considerados pela academia ocidental como parte dos novos movimentos sociais capazes de apresentar uma nova agenda com a possibilidade de ampliar os horizontes dos direitos humanos de terceira geração.

Com o conceito de estado plurinacional, os movimentos indígenas exigem uma nova forma de contratilidade e sociabilidade para acomodar as diferenças que permeiam a sociedade em um plano plurinacional. Isso significa que o Estado deve ser reconstruído de tal maneira que a ordem jurídica incorpore as diferenças radicais que constituem a sociedade. No Equador, em 2008, e na Bolívia, em 2009, o discurso de vivir buen ou buen vivir se tornou oficial e o conceito foi integrado às constituições daqueles países, resultando em um estado plurinacional. A plurinacionalidade exige o reconhecimento da constituição étnica e epistemológica do território nacional, e o conceito de interculturalidade exige que haja igualdade entre todas as pessoas, resultando em emancipação, distribuição de riqueza e inclusão social. Segundo Walsh, esse movimento

preocupa-se em recuperar a dimensão molecular do social e em aprofundar a democracia e a cidadania do mundo. A equidade, a democracia, a participação, a proteção da biodiversidade e dos recursos naturais e o respeito à diversidade étnico-cultural servem como elementos-chave do quadro ${ }^{16}$.

A inclusão do buen vivir ${ }^{17}$ nas constituições pode ser entendida como um grande avanço. Na Constituição da Bolívia, o conceito de buen vivir é introduzido no preâmbulo, bem como no segundo capítulo, reconhecendo-o como um princípio ético vinculado à organização econômica do Estado. Na Constituição boliviana, a natureza não é reconhecida como sujeito de direito e a natureza não possui valores intrínsecos.

\footnotetext{
16 WALSH, Catherine. Development as Buen Vivir: Institutional arrangements and (de)colonial entanglements. Development, año 53, p. 15-21, 2010. p. 16.

17 WALSH, 2010, p. 17
} 
Já na Constituição do Equador, a natureza é um tema consagrado com direitos. O desenvolvimento está de acordo com o buen vivir exigido para cumprir os direitos da Pachamama (natureza).

Não há dúvida de que o buen vivir como conceito pós-desenvolvimento pode contribuir imensamente com as sociedades contemporâneas, nas quais o desenvolvimento chegou ao seu limite, e poderia se tornar um projeto político. ${ }^{18}$ Para os grupos indígenas é também uma oportunidade de conquistar um espaço na sociedade. Os problemas aparecem quando surgem divisões entre os líderes indígenas e ocorrem alianças ou rupturas com os governos. Isso resulta no fortalecimento do interesse e das posições do sistema mundial colonial, ainda dominante, que compromete a consolidação do projeto plurinacional de uma sociedade e Estado intercultural. Além disso, tal projeto não pode ser imposto violentamente nem pode ser concebido a partir de uma ideia romântica de que todos têm que aceitar o buen vivir como uma maneira de retornar aos tempos antigos de solidariedade e retribuição comunitária. Considerando os resultados desse projeto, podem-se perceber três possibilidades à frente, segundo Vásquez: "mais cedo ou mais tarde, pode terminar como uma extravagância de curta duração"; pode tornar-se "uma versão domesticada do desenvolvimento humano integral e sustentável enquadrado na grande coleção de desenvolvimento" (social, humano, integral etc.); e, por fim, pode se tornar "uma verdadeira revolução cultural"19.

A Teologia da Libertação latino-americana, desde seus primórdios, reconheceu, apoiou e dialogou com diferentes contextos, como na luta em defesa de uma economia justa, de solidariedade com os oprimidos e os pobres, pela ecologia e pelo diálogo com outros movimentos religiosos. As discussões sobre a inculturação e a reflexão sobre a ecologia contribuíram com grandes mudanças na discussão teológica entre os teólogos latino-americanos e promoveram uma articulação da Teologia da Libertação com a Teologia do Pluralismo Religioso. ${ }^{20}$ Essa é uma nova abordagem para um diálogo ecumênico que é aberto e respeitoso com pessoas e teologias. Neste sentido, trazer essa perspectiva em diálogo com as igrejas cristãs é um desafio especial para a Teologia Prática.

\section{Teologia Prática em diálogo com o buen vivir}

Neste último tópico, pretende-se aprofundar o diálogo mais específico entre a Teologia Prática e o buen vivir. As perguntas que se colocam a nós, neste contexto, estão relacionadas à contribuição e ao impacto de um princípio de vida, da margem, tão amplo e rico como o buen vivir para a Teologia Prática, em tempos de crise da própria Teologia Prática em nosso contexto. Também cabe aqui perguntar sobre a

${ }^{18}$ ESCOBAR, Arturo. Una minga para el postdesarrollo. Lima: Universidad Nacional Mayor de San Marcos, 2010. p. 181.

19 VÁZQUEZ, Andrés Uzeda. Del vivir buen y del vivir la vida. Revista teológica y pastoral/ISEAT, La Paz, año 17, p. 40-50, 2010. p. 49.

${ }^{20}$ BAPTISTA, Paulo Agostinho N. Globalização e as teologias da libertação e do pluralismo religioso. Horizonte, ano 5, n. 9, p. 54-79, 2006. p. 54. 
relação entre buen vivir e Teologia da Libertação, pensando o buen vivir como algo que redimensiona tanto a Teologia da Libertação como a Teologia Prática. Ou seja, o buen vivir, mais que algo novo, torna-se um novo impulso na dimensão das novas epistemologias da margem e do pensamento pós-colonial, para repensar a Teologia na América Latina. Nesta reflexão, tomaremos, a princípio, a Teologia Prática de forma clássica e ampla, como uma reflexão não só da prática da igreja, mas também como reflexão da prática $d a$ teologia ou uma teologia $d a$ prática, com vistas a uma práxis libertadora na realidade concreta da vida e das lutas. ${ }^{21}$

Na América Latina, muito importante foi e é pensar a relação entre Teologia Prática e Teologia da Libertação (TdL), como já referimos, porque a TdL abriu uma perspectiva singular no relacionamento entre teoria e prática, de forma que uma fortaleceu a outra. Retomemos algumas características da TdL.

A TdL desenvolve-se a partir da década de 1960 como uma teologia contextual, como forma clara de nomear a realidade e denunciar a vulnerabilidade histórica e estrutural da sociedade. Inspirada, dentre outras, nas teologias da esperança (J. Moltmann) e na teologia política (J. B. Metz), gestada na práxis pastoral junto a comunidades eclesiais de periferia, depois expressa nas Conferências Episcopais Latino-Americanas (CELAM) da Igreja Católica, em Medellín (1968) e Puebla (1979), a TdL nasceu como opção pelos pobres, propondo uma teologia claramente voltada para a realidade de profunda vulnerabilidade humana em busca da justiça social e superação da violência estrutural. Em meio a ditaduras militares articuladas contra organizações e movimentos sociais, populares, a TdL elabora uma nova cristologia, que consequentemente vai gerar uma nova eclesiologia, as comunidades eclesiais de base $(\mathrm{CEBs})^{22}$, onde a práxis de libertação e o método ver-julgar-agir provocariam grandes mudanças na sociedade, mas principalmente na igreja e na própria teologia. Consequentemente, a igreja é entendida como uma igreja que se faz povo, a igreja dos pobres, uma igreja incorporada na vida dos pobres. Jesus Cristo é encontrado no rosto do pobre. Deus vai ser imaginado como gente, como povo, como pobre. Concebe-se um Deus que não só se aproxima, mas assume a condição e as feições do pobre.

Nas últimas décadas, a TdL se abre para novos apelos de libertação, como as questões de gênero, a questão indígena, a questão dos afrodescendentes, a questão do pluralismo religioso e o desafio ecológico, assumindo a nomenclatura plural de Teologias Latino-Americanas da Libertação, com novos imaginários e figuras para representar e expressar Deus. ${ }^{23}$

${ }^{21} \mathrm{HOCH}$, Lothar Carlos. O lugar da Teologia Prática como disciplina teológica. In: SCHNEIDER-HARPPRECHT, Christoph; ZWETSCH, Roberto E. (Orgs.). Teologia prática: no contexto da América Latina. 3. ed. revista e ampliada. São Leopoldo: Sinodal; EST, 2011. p. 23-35.

${ }^{22}$ Sobre as CEBs, cf. TEIXEIRA, Faustino L. C. A gênese das CEBs no Brasil: elementos explicativos. São Paulo: Paulinas, 1988.

${ }^{23}$ BARROS, Marcelo. A reconciliação de quem nunca se separou. Pluralismo cultural e religioso: eixo da Teologia da Libertação. Disponível em: <http://servicioskoinonia.org/relat/353p.htm>. Acesso em: 10 ago. 2018. 
Além de ser eminentemente voltada para a prática, a TdL situa a reflexão teológica social e politicamente. Teologia passa a ser articulada no aqui e no agora, em meio à vida das pessoas, onde a palavra de Deus ganha vida concreta e onde as mazelas humanas - hoje também ambientais - precisam ser transformadas. Na relação entre teoria e prática da TdL, Libanio aponta três âmbitos: uma teologia $d a$ práxis, na medida em que toma a prática das comunidades de fé como base da sua reflexão; uma teologia na prática, na medida em que o teólogo está inserido nas lutas da comunidade; uma teologia para a prática, na medida em que ela se propõe a oferecer subsídios para aqueles que estão envolvidos nas lutas por transformação. De modo que podemos dizer que a TdL colocou a teologia como sendo aquilo que a Teologia Prática sempre tentou ser: teologia $n a$, para e a partir da prática. ${ }^{24}$

Neste sentido, fica muito evidente a relação próxima entre TdL e o buen vivir, como um pensamento-prático, da margem, como parte das hermenêuticas descoloniais $^{25}$, como forma não só de fortalecimento dos povos indígenas, mas também como base para pensar outras formas de ser e estar no mundo, em um horizonte pós-capitalista, necessário e urgente, como diz Boaventura de Sousa Santos:

[...] el Sumak Kawsay (quechua) de Ecuador, o el Sumak Qamaña (aymara) en Bolivia, los principios del "buen vivir" o vivir bien que son otros conceptos civilizatorios, otra manera de no usar la palabra desarrollo, y defender otras relaciones con la Madre Tierra y la naturaleza. Los derechos de la Naturaleza constan en la Constitución Política de Ecuador. Aquí está realmente el cambio civilizatorio, ya presente en textos constitucionales, que puede aplicarse o no, pero están en la agenda política ${ }^{26}$.

Com base no buen vivir, Quijano reforça a crucial possibilidade de uma nova forma de sociedade global.

Lo que aquí propongo es abrir una cuestión crucial de nuestro crucial período histórico: bien vivir, para ser una realización histórica efectiva, no puede ser sino un complejo de prácticas sociales orientadas a la producción y a la reproducción democráticas de una sociedad democrática, un otro modo de existencia social, con su propio y específico

24 Apud HOCH, 2011, p. 30.

25 Sobre a relação entre Teologia da Libertação e o pensamento descolonial, cf. BAPTISTA, Paulo Agostinho Nogueira. Pensamento decolonial, teologias pós-coloniais e teologia da libertação. Perspectiva Teológica, Belo Horizonte, v. 48, n. 3, p. 491-517, set./dez. 2016.

26 “"...] o Sumak Kawsay (Quechua) do Equador, o Sumak Qamaña (Aymara) na Bolívia, os princípios de 'viver bem' vivendo bem, que são outros conceitos civilizatórios, uma outra maneira de não usar a palavra desenvolvimento, e defender outras relações com a Mãe Terra e a natureza. Os direitos da natureza estão incluídos na Constituição Política do Equador. Aqui está realmente a mudança civilizacional, já presente em textos constitucionais, que podem ser aplicados ou não, mas estão na agenda política." LOPERA, Gladys; NAVARRO COLORADO, Fernando. Entrevista a Boaventura de Souza Santos. Disponível em: <//C:/Users/Adam/Downloads/229-242_ENTREVISTA.pdf>. Acesso em: 10 ago. 2018. 
horizonte histórico de sentido, radicalmente alternativos, respectivamente, a la Colonialidad Global del Poder y a la Colonialidad/Modernidad/Eurocentrada. ${ }^{27}$

Como se dá esse diálogo é também algo importante a ser considerado. Em um contexto de efervescência religiosa e muitas experiências diversificadas, como se verifica na realidade latino-americana, o diálogo com o buen vivir também deve ser estabelecido na base e não apenas no mundo acadêmico. Deveria estar acontecendo onde as pessoas estão articulando suas crenças, sua fé e sua vida, como propõe a Teologia da Libertação. Ou seja, no diálogo com a TdL há um esforço por evitar apossar-se acadêmica ou ideologicamente dessa experiência-vivência andina com o mesmo espírito colonialista e utilitarista que predominou durante os 500 anos de domínio europeu no continente. ${ }^{28} \mathrm{O}$ buen vivir é algo amplo e profundo, e não deveria ser tomado pelo pensamento racional, de forma ocidentalizante. O buen vivir faz parte dos processos de descolonização ${ }^{29}$, como veremos a seguir.

A pergunta que deveria embalar o diálogo é, justamente, pela possibilidade de a partir do buen vivir repensar a própria TdL e, consequentemente, a Teologia Prática, levando-as a outro nível de reflexão e prática que realmente promova vida íntegra e justa, no sentido do que foi abordado no primeiro tópico deste artigo, algo que não é fácil. Como aponta Quispe, pensar a Teologia Prática a partir do buen vivir é dar espaço para uma nova experiência e uma nova prática:

Asumir el desafío de la articulación entre teología y Buen Vivir no es tarea fácil por la fuerte connotación académica de la teología, en la que aún prima el racionalismo sobre la vivencia. Sin embargo, el proceso metodológico del quehacer teológico en América Latina, que plantea la experiencia como acto primero, nos abre puertas al diálogo entre teología y Buen Vivir que se nutre de las cosmovisiones y espiritualidades de los pueblos indígenas y otras espiritualidades que buscan la vida digna en esta nuestra gran casa común ${ }^{30}$.

27 “O que proponho aqui é abrir uma questão crucial do nosso crucial período histórico: viver bem, para ser uma realização histórica eficaz, só pode ser um complexo de práticas sociais orientadas para a produção e reprodução democráticas de uma sociedade democrática, de outra forma da existência social, com seu próprio horizonte histórico específico de significado, radicalmente alternativo, respectivamente, à Colonialidade Global do Poder e à Colonialidade / Modernidade / Eurocentrada.” QUIJANO, Aníbal. ¿Bien vivir?: entre el "desarrollo" y la descolonialidad del poder. Disponível em: <http://www.vientosur.info/ IMG/pdf/VS122_A_Quijano_Bienvivir---.pdf>. Acesso em: 24 set. 2015.

28 SCHNEIDER-HARPPRECHT, Christoph. Perspectivas da Teologia Prática no Brasil e na América Latina. In: SCHNEIDER-HARPPRECHT; ZWETSCH (Orgs.), 2011, p. 281-290.

29 QUISPE, Sofía Chipana. Teología y Buen Vivir. In: FUNDACIÓN AMERÍNDIA (Coord.). La teología de la liberación en prospectiva: talleres y paneles. Montevideo: Doble Clic, 2012. p. 237.

30 "Assumir o desafio da articulação entre teologia e Bem Viver não é tarefa fácil por causa da forte conotação acadêmica da teologia, em que o racionalismo prevalece sobre a experiência. No entanto, o processo metodológico do trabalho teológico na América Latina, que suscita a experiência como primeiro ato, abre as portas para o diálogo entre a teologia e o Bem-viver, alimentado pelas cosmovisões e espiritualidades dos povos indígenas e outras espiritualidades que buscam a vida digna nesta nossa grande casa comum." QUISPE, 2012, p. 233. 
Podemos dizer, assim, que buen vivir escapa aos conceitos e preceitos comuns da Teologia, pois buen vivir tem a ver com vivência, experiência, sonhos, memórias mais do que princípios e verdades, no sentido clássico da teologia. Como formula a teóloga Sofía Chipana Quispe:

En el contexto andino donde surge como palabra enunciada el Sumak Kawsay - Buen Vivir, el Suma Qamaña - vivir bien, no son términos usados con frecuencia, ya que en los ámbitos quechuas (quichuas) o aymaras, se las usa para expresar realidades soñadas y buscadas; así la palabra se hace vida al sentirlo, soñarlo y lucharlo; en ese sentido la palabra es evocada desde la memoria ancestral para adquirir mayor sentido y fuerza ${ }^{31}$.

Ou seja, na medida em que valoriza a experiência mais do que os conceitos, o diálogo da teologia e da Teologia Prática com o buen vivir impulsiona para algo maior: repensar a grande crise civilizacional, a crise do paradigma ocidental que estamos vivendo:

En estos últimos tiempos, de manera pertinente lo que se intenta es demostrar que el Buen Vivir, más que un concepto, es una vivencia-experiencia que integra toda la vida, y es válido para unas sociedades que ven que: [El] paradigma occidental moderno está en crisis y con ello los modelos económicos y políticos que surgieron con esta misma modernidad: el capitalismo (neo) liberal y el Estado democrático liberal ${ }^{32}$.

Essa crise do modelo ocidental se reflete na crise da própria Teologia Prática em nosso contexto. Assim como em países do $\mathrm{Norte}^{33}$, a crise da Teologia Prática no contexto latino-americano reflete uma crise maior, a crise da própria teologia e uma crise da própria igreja. Mesmo a TdL, como uma teologia que colocou a vulnerabilidade da América Latina e de outros contextos e grupos como lugar hermenêutico válido para a teologia ${ }^{34}$, enfrenta hoje desafios sem precedentes diante da pobreza que persiste no continente, a degradação ambiental, a falta de projetos sociais, a perda da utopia e da esperança, o individualismo e a banalização da vida, o consumismo e o abandono de tradições e costumes autóctones, como resultado da globalização. No campo religioso, cresce no continente o chamado mercado religioso, aliado a uma teologia de cunho individualista, fundamentalista e orientada para a prosperidade econômica.

Vemos assim o quanto a experiência do buen vivir desafia a teologia, a Teologia Prática e a igreja e organizações populares a se rearticularem e a se repensarem em um tempo de crise paradigmática. Qual o papel da Teologia Prática para as igrejas protestantes históricas diante desse cenário? Mais do que definição, a Teologia Prática precisa buscar seu elemento próprio ${ }^{35}$ e se reinventar como teologia a partir da prática, na

${ }^{31}$ QUISPE, 2012, p. 234.

${ }^{32}$ QUISPE, 2012, p. 238.

33 GANZEVOORT, R. Ruard. Encruzilhadas do caminho no rastro do sagrado. Estudos Teológicos, São Leopoldo, ano 49, n. 2, p. 317-343, 2009.

${ }^{34} \mathrm{HOCH}, 2011$.

${ }^{35}$ SCHNEIDER-HARPPRECHT, 2011, p 287ss. 
prática, e para a prática. ${ }^{36} \mathrm{O}$ buen vivir, como um pensamento da margem, como uma vivência-experiência, pode ser um excelente caminho para o encontro desse elemento próprio, possibilitando não só enfrentar a crise, mas uma reinvenção da própria Teologia Prática. Essa reinvenção não seria meramente uma adaptação. É realmente permitir-se reinventar a partir de um diálogo profundo com a vivência-experiência de um local, levando a sério suas crenças, culturas e prática da vida comum. Nesse sentido, Quispe chega a falar de descolonizar o próprio cristianismo ${ }^{37}$, e Barros desafia a Teologia da Libertação a abrir-se inclusive para uma Teologia do Pluralismo Religioso como nova e necessária abrangência da TdL. ${ }^{38}$

O que significa esse diálogo para a Teologia Prática? Pelo menos três aspectos terão que ser levados em conta: a) a aprendizagem baseada nas culturas e práticas locais, o conhecimento das margens, deixando-se moldar pela sabedoria da vida local; b) a compreensão da totalidade da vida, entendendo que pessoas, comunidades, tradições e natureza são todos protagonistas ativos e formam um todo integrado. O buen vivir é muito mais do que a vida bem determinada pelo programa capitalista de qualidade de vida. Buen vivir é permitir que tudo fique bem, garantindo a sustentabilidade e a dignidade de tudo e de todos; c) redescobrir a dimensão ecológica e ambiental como tema imprescindível da teologia e da Teologia Prática. ${ }^{39}$

Novos impulsos e iniciativas, não só no espaço acadêmico, mas também na prática, já acontecem em nosso meio como parte desse instigante exercício dialógico com o buen vivir. O relato a seguir é um desses exemplos. No mês de abril, lembramos no Brasil os povos indígenas. No culto semanal na Faculdades EST, integrantes do Conselho de Missão entre os Povos Indígenas (COMIN) organizaram um culto diferente. As cadeiras foram organizadas em forma circular. No centro havia uma grande mesa com comidas das várias tradições indígenas. Todo o tema do culto tratava de solidariedade e de compartilhamento como parte das culturas indígenas brasileiras. Durante o sermão, baseado em Mateus 14.13-21, foi destacado o tema da partilha e da solidariedade como impactante boa nova. Declarações de mulheres indígenas foram lidas:

Os Kaingang dividem tudo. Eles não guardam as coisas para eles mesmos. Nós gostamos de compartilhar tudo. Eu compartilho comida com as pessoas que vêm à minha casa. Nós gostamos de compartilhar e comer juntos. Nós vivemos bem com a natureza, com o que ela nos dá, com o que ela nos oferece.

Ou ainda outro depoimento:

Um aspecto da cultura do meu povo e do que está dentro de mim, que é algo muito importante para mim, é compartilhar. Nós não deixamos a casa da minha mãe com as

${ }^{36} \mathrm{HOCH}, 2011$.

${ }^{37}$ QUISPE, 2012, p. 242.

${ }^{38}$ BARROS, Marcelo. A reconciliação de quem nunca se separou do pluralismo cultural e religioso: eixo da Teologia da Libertação. Disponível em: $<\mathrm{http}: / /$ servicioskoinonia.org/relat $/ 353 \mathrm{p} . \mathrm{htm}>$. Acesso em: 10 ago. 2018.

${ }^{39}$ BOFF, Leonardo. Saber cuidar: ética do humano - compaixão pela terra. 9. ed. Petrópolis: Vozes, 2003. 
mãos vazias. Compartilhar o pouco que se tem com quem não tem. Pensamos no outro, nos preocupamos com o outro.

O culto terminou com toda a comunidade reunida em torno da grande mesa, compartilhando a comida das culturas indígenas. Muitos dos alimentos eram conhecidos a partir da dieta diária dos brasileiros, mas nem sabíamos a sua verdadeira origem. Isso nos ensinou que nem mesmo sabemos tudo o que os povos indígenas compartilham do seu legado histórico.

Esse culto, na sua simplicidade e novidade, conseguiu reunir várias áreas do estudo da Teologia Prática: liturgia, pregação, serviço, comunhão, ensino, interação comunitária, reflexão política, eclesiologia e missão. Tudo isso está relacionado aos princípios básicos do buen vivir. O próprio COMIN, em seu trabalho missionário em conjunto com os povos indígenas, refletiu sobre o buen vivir e descobriu aspectos desse princípio - como aqui a solidariedade e o compartilhamento - bem como nas tradições indígenas em todo o território brasileiro ${ }^{40}$, algo que pode ser dito com as palavras de Quispe, quando explica o buen vivir:

Se trata de palabras que no sólo se expresan a través del lenguaje verbal, sino que rememoran eventos significativos, sueños y esperanzas que se comunican de diversos modos, ya que en el mundo indígena todo habla; por lo tanto, el Buen Vivir es comunicado a través de la música, la danza, la comida, los tejidos, la lluvia, la tierra, las y los otras/os seres, la vida misma ${ }^{41}$.

Nas subáreas da Teologia Prática, os resultados de um diálogo com o buen vivir podem tornar-se bastante ricos, como já se pode perceber no exemplo do culto acima. Nos âmbitos da liturgia e da homilética - a ampliação da inculturação litúrgica, a abertura ao ecumenismo e ao diálogo inter-religioso, além da redescoberta da festividade como expressão subversiva de esperança; ${ }^{42}$ a redescoberta da dimensão anamnésica, da memória perigosa ${ }^{43}$, a redescoberta de uma pregação cristã como espaço de leitura e interpretação compartilhada da Palavra e de uma pregação imbuída na vida ${ }^{44}$, são algumas das possibilidades. Na área da diaconia, a criação de espaço para pensar e vivenciar a radicalidade do compartilhar à mesa, novas formas de se relacionar com a alimentação e compartilhar a comida ${ }^{45}$, além do fortalecimento da vida comunitária

${ }^{40}$ TREIN, Hans A. Bem Viver na criação, alternativa de esperança e compromisso. In: MARKUS, Cledes; GIERUS, Renate (Eds.). O bem viver na Criação. São Leopoldo: OIKOS, 2013. p. 85-98.

${ }^{41}$ QUISPE, 2012, p. 236.

42 ADAM, Júlio Cézar. Worship with a Brazilian Face: Dialogue between Culture and Worship as a Way for Caring for and Transforming Life. In: WILKEY, Gláucia Vasconcelos (Ed.). Worship and Culture: Foreign Country or Homeland? Grand Rapids; Cambridge: Eerdmans, 2014. p. 239-261.

${ }^{43}$ METZ, Johann Baptist. Zukunft aus dem Gedächtnis des Leidens: eine gegenwärtige Gestalt der Verantwortung des Glaubens. Concilium, n. 8, p. 399-407, 1972.

44 ADAM, Júlio Cézar. Mal-estar no púlpito: repensando teologicamente a pregação cristã na sociedade da informação. Estudos Teológicos, São Leopoldo, ano 53, n. 1, p. 160-175, 2013.

${ }^{45}$ GAEDE NETO, Rodolfo. Banquetes de vida: a diaconia nas comunhões de mesa de Jesus. Estudos Teológicos, São Leopoldo, ano 50, n. 2, p. 306-318, 2010. 
e coletiva, podem ser enriquecidos com o projeto buen vivir. Também a articulação de um aconselhamento pastoral que, ao mesmo tempo, cuida da pessoa, do indivíduo e se amplia para uma rede viva, considerando fatores sociais e políticos que afetam a vida das pessoas. ${ }^{46}$ Uma educação cristã fundada na troca de saberes (Paulo Freire) e na possibilidade de uma saudável articulação do Evangelho como um contínuo viver do batismo pode encontrar no buen vivir fortes ressonâncias. Acima de tudo, contudo, buen vivir deveria encontrar ressonância no próprio Evangelho, possibilitando novas formas de ser igreja e comunidade nesta realidade, articulando e recriando uma nova eclesiologia apropriada ao contexto, uma igreja que promove a vida em abundância e que transforma as muitas vulnerabilidades em alternativas de boa vida.

\section{Conclusão}

Iniciamos o texto dizendo que a teologia está desafiada a identificar, explicitar e ajudar a construir novos caminhos para lidar com as pessoas e com o contexto social e natural no qual vivem. O cristianismo de libertação apontou novas dimensões do trabalho pastoral a partir do envolvimento e comprometimento com a realidade, revelando também a sua complexidade. As discussões sobre inculturação, gênero, raça e ecologia aos poucos foram sendo incorporadas na Teologia de Libertação e contribuíram para mudanças na discussão teológica e também no próprio fazer teologia. A abertura para outras religiões e culturas ampliou o diálogo ecumênico, permitindo ver convergências e diferenças para construir visões de mundo e projetos de sociedade mais integradores.

O buen vivir, como procuramos argumentar, é um exemplo das aprendizagens que o diálogo com as culturas andinas da América do Sul proporciona, com sua maneira de saber, de relacionar-se com o outro, com a natureza e com o sagrado. A Teologia Prática, por sua vez, é um lugar privilegiado para praticar e exercitar a aproximação com essas experiências muitas vezes menosprezadas como atrasadas ou simplesmente esquecidas e silenciadas. A liturgia, o ensino, o aconselhamento pastoral, a diaconia e outras dimensões da vida comunitária e eclesial podem ser enriquecidas e tornadas mais densas de sentido humano ao abrir-se para essas experiências milenares.

Esse pensamento prático, da margem, como parte das hermenêuticas descoloniais, não é só de fortalecimento dos povos indígenas, mas também serve como base para pensar outras formas de ser e estar no mundo. Conforme o teólogo Paulo Suess:

o conceito de Bem Viver não é uma receita ou um manual de aplicação, mas um horizonte que nos faz caminhar, discernir e lutar pela redistribuição dos bens do Planeta (terra, água, ar) e pelo reconhecimento do outro e da outra, não em relações concorrenciais, mas de reciprocidade e gratuidade ${ }^{47}$.

${ }^{46}$ MILLER-McLeMORE, Bonnie J. Teologia Pastoral como Teologia Pública. Estudos Teológicos, São Leopoldo, ano 52, n. 1, p. 75-98, 2012.

47 SUESS, Paulo. A luta pelo território: o centro simbólico e real do Bem Viver. Entrevista especial com Paulo Suess. Disponível em: <http://www.ihu.unisinos.br/159-noticias/entrevistas/525351-a-luta-pelo- 
O buen vivir é uma memória que os povos andinos têm de seus antepassados e que ajuda a sonhar e agir para mudar a vida no planeta para que todos tenham vida em abundância.

\section{Referências}

ACOSTA, Alberto. El Buen Vivir, una oportunidad por construir. Equador debate, n. 75, p. 33-48, 2018.

ADAM, Júlio Cézar. Mal-estar no púlpito: repensando teologicamente a pregação cristã na sociedade da informação. Estudos Teológicos, São Leopoldo, ano 53, n. 1, p. 160-175, 2013.

. Worship with a Brazilian Face: Dialogue between Culture and Worship as a Way for Car-

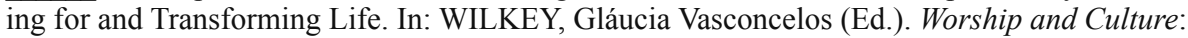
Foreign Country or Homeland? Grand Rapids; Cambridge: Eerdmans, 2014. p. 239-261.

AYALA, Felipe Guamán Poma de. Nueva Corónica y Buen Gobierno. México: Fondo de Cultura Económica, 1993.

BAPTISTA, Paulo Agostinho N. Globalização e as teologias da libertação e do pluralismo religioso. Horizonte, ano 5, n. 9, p. 54-79, 2006

BARROS, Marcelo. A reconciliação de quem nunca se separou. Pluralismo cultural e religioso: eixo da Teologia da Libertação. Disponível em: <http://servicioskoinonia.org/relat/353p.htm>. Acesso em: 10 ago. 2018.

BOFF, Leonardo. Saber cuidar: ética do humano - compaixão pela terra. 9. ed. Petrópolis: Vozes, 2003.

. Evangelho do Cristo Cósmico. A busca da unidade do Todo na ciência e na religião. Rio de Janeiro: Record, 2008.

CORTEZ, David. La construcción social del 'Buen Vivir' (Sumak Kawsay) en Ecuador Genealogía del diseño y gestión política de la vida. Aportes Andinos, n. 28, p. 1-23, 2011.

DÁVALOS, Pablo. Reflexiones sobre el sumak kawsay (buen vivir) y las teorías del desarrollo. ALAI (Agencia Latino Americana de Informaciones), Quito, 2008. Disponível em: <http:// alainet.org/active/25617>. Acesso em: 10 ago. 2018.

DUSSEL, Enrique. 1942: O encobrimento do outro: A origem do mito da modernidade. Petrópolis: Vozes, 1993.

ESCOBAR, Arturo. Una minga para el postdesarrollo. Lima: Universidad Nacional Mayor de San Marcos, 2010.

FELIX, Gloria Alicia Caudillo. El buen vivir: un diálogo intercultural. Ra-Ximhai, año 8, n. 2, p. $345-363,2012$.

GAEDE NETO, Rodolfo. Banquetes de vida: a diaconia nas comunhões de mesa de Jesus. Estudos Teológicos, São Leopoldo, ano 50, n. 2, p. 306-318, 2010.

GANZEVOORT, R. Ruard. Encruzilhadas do caminho no rastro do sagrado. Estudos Teológicos, São Leopoldo, ano 49, n. 2, p. 317-343, 2009.

GUDYNAS, Eduardo. Buen Vivir: Today's tomorrow. Development, ano 54, n. 4, p. 441-447, 2011.

HOCH, Lothar Carlos. O lugar da Teologia Prática como disciplina teológica. In: SCHNEIDER-HARPPRECHT, Christoph; ZWETSCH, Roberto E. (Orgs.). Teologia prática: no contexto da América Latina. 3. ed. revista e ampliada. São Leopoldo: Sinodal; EST, 2011. p. 23-35.

LOPERA, Gladys; NAVARRO COLORADO, Fernando. Entrevista a Boaventura de Souza Santos. Disponível em: <///C:/Users/Adam/Downloads/229-242_ENTREVISTA.pdf>. Acesso em: 10 ago. 2018.

-territorio-o-centro-simbolico-e-real-do-bem-viver-entrevista-especial-com-paulo-suess $>$. Acesso em: 07 nov. 2013. 
LÖWY, Michel. The historical meaning of Christianity of Liberation in Latin America. In: MORAÑA, Mabel; DUSSEL, Enrique; JÁUREGUI, Carlos (Ed.). Coloniality at large: Latin America and the Postcolonial debate. Durham; London: Duke University Press, 2008. p. 351-359. METZ, Johann Baptist. Zukunft aus dem Gedächtnis des Leidens: eine gegenwärtige Gestalt der Verantwortung des Glaubens. Concilium, n. 8, p. 399-407, 1972.

MILLER-McLEMORE, Bonnie J. Teologia Pastoral como Teologia Pública. Estudos Teológicos, São Leopoldo, ano 52, n. 1, p. 75-98, 2012.

PIKETTY, Thomas. O capital no século XXI. Trad. Monica Baumgarten de Bolle. Rio de Janeiro: Intrínseca, 2014.

QUIJANO, Aníbal. ¿Bien vivir?: entre el “desarrollo” y la descolonialidad del poder. Disponível em: < http://www.vientosur.info/IMG/pdf/VS122_A_Quijano_Bienvivir---.pdf $>$. Acesso em: 24 set. 2015.

QUIJANO, Anibal. Coloniality of Power, Eurocentrism, and Latin America. In: MORAÑA, Mabel; DUSSEL, Enrique; JÁUREGUI, Carlos (Ed.). Coloniality at large: Latin America and the Postcolonial debate. Durham; London: Duke University Press, 2008. p. 181-224.

QUISPE, Sofía Chipana. Teología y Buen Vivir. In: FUNDACIÓN AMERÍNDIA (Coord.). La teología de la liberación en prospectiva: talleres y paneles. Montevideo: Doble Clic, 2012. p. 233-262.

SANTOS, Boaventura de Sousa; MENESES, Maria Paula (Ed.). Epistemologias do Sul. São Paulo: Cortez, 2010.

SANTOS, Boaventura de Sousa. ¿Dualidad de poderes o ecología de saberes? La Paz: Red Boliviana de Mujeres Transformando la Economía REMTE, 2012. (Cuaderno de Trabajo, 18). SCHNEIDER-HARPPRECHT, Christoph. Perspectivas da Teologia Prática no Brasil e na América Latina. In: SCHNEIDER-HARPPRECHT, Christoph; ZWETSCH, Roberto E. (Orgs.). Teologia prática no contexto da América Latina. 3. ed. revista e ampliada. São Leopoldo: Sinodal; EST, 2011. p. 281-290.

SUESS, Paulo. A luta pelo território: o centro simbólico e real do Bem Viver. Entrevista especial com Paulo Suess em 07.11.2013. Disponível em: <http://www.ihu.unisinos.br/159-noticias/ entrevistas/525351-a-luta-pelo-territorio-o-centro-simbolico-e-real-do-bem-viver-entrevista-especial-com-paulo-suess>. Acesso em: 24 jul. 2018.

TREIN, Hans A. Bem Viver na criação, alternativa de esperança e compromisso. In: MARKUS, Cledes; GIERUS, Renate (Eds.). O bem viver na Criação. São Leopoldo: OIKOS, 2013. p. 85-98. VAZQUEZ, Andrés Uzeda. Del vivir buen y del vivir la vida. Revista teológica y pastoral/ISEAT, La Paz, año 17, p. 40-50, 2010.

WALSH, Catherine. Development as Buen Vivir: Institutional arrangements and (de)colonial entanglements. Development, ano 53, p. 15-21, 2010. 